\title{
IncRNA PICART1 alleviates progression of cervical cancer by upregulating TCF21
}

\author{
YUNXIA ZHAO, XIUXIAN DONG and RONG HOU \\ Department of Gynaecology and Obstetrics, Weifang People's Hospital, Weifang, Shandong 261041, P.R. China
}

Received October 23, 2019; Accepted December 19, 2019

DOI: 10.3892/ol.2020.11486

\begin{abstract}
Role of long non-coding RNA (lncRNA) PICART1 in alleviating the progression of cervical cancer $(\mathrm{CC})$ via targeting TCF21 was elucidated. PICART1 level in CC and paracancerous tissues was determined by quantitative realtime polymerase chain reaction (qRT-PCR). Its level in CC patients with different tumor stages (stage I+II and stage III+IV) and tumor sizes $(\leq 4 \mathrm{~cm}$ and $>4 \mathrm{~cm})$ was examined. Survival analysis was conducted in CC patients expressing high level and low level of PICART1. Changes in proliferative, migratory and invasive abilities of HeLa and SiHa cells after transfection of si-PICART1 were assessed. Prognostic value of TCF21 in CC was determined by Kaplan-Meier curves. The interaction between PICART1, TCF21 and ARID1A was investigated through RNA immunoprecipitation (RIP) and Chromatin immunoprecipitation (ChIP) assay. PICART1 was downregulated in CC tissues and cell lines. CC patients with worse TNM staging and larger tumor size presented lower level of PICART1. Low level of PICART1 in CC patients predicted a worse prognosis. Silence of PICART1 stimulated the proliferative, migratory and invasive abilities of HeLa and SiHa cells. TCF21 expression was low in $\mathrm{CC}$ tissues and positively regulated by PICART1. Low level of TCF21 in CC patients predicted a worse prognosis. Potential binding relationship was verified among PICART, ARID1A and TCF21. ChIP assay confirmed the decreased enrichment of ARID1A in TCF21 promoter region after PICART1 knockdown. IncRNA PICART1 recruits ARID1A to activate TCF21 expression, thus alleviating the malignant progression of $\mathrm{CC}$.
\end{abstract}

\section{Introduction}

Cervical cancer (CC) is a prevelant female malignancy with a high mortality. In 2012, there were 527,600 newly onset cases and 265,700 death cases globally (1). With advance

Correspondence to: Dr Rong Hou, Department of Gynaecology and Obstetrics, Weifang People's Hospital, 151 Guangwen Street, Kuiwen, Weifang, Shandong 261041, P.R. China

E-mail: hourong740818@163.com

Key words: cervical cancer, lncRNA PICART1, ARID1A, TCF21 in the screening technologies and therapeutic strategies, the incidence and mortality of CC are on the decline (2). Nevertheless, the overall survival of CC patients is poor (3). Effective hallmarks that predict the occurrence and progression of CC are lacking. Currently, squamous cell carcinoma antigen (SCC-Ag) is commonly applied for diagnosing CC (4). However, the sensitivity and specificity of SCC-Ag are relatively low, which markedly restricts its clinical application. It is necessary and urgent to uncover efficient diagnostic markers for $\mathrm{CC}$.

Long non-coding RNAs (lncRNAs) are widely expressed in mammals and regulate gene expression. They are able to mediate various cellular behavior $(5,6)$. IncRNAs influence the occurrence and progression of tumors as oncogenes or tumorsuppressor genes (7). It is reported that lncRNAs form different types of complexes alongside many factors, thus directly regulating downstream genes and affecting malignant phenotypes of tumor cells (8). Several abnormally expressed lncRNAs have been identified in CC. These IncRNAs may be utilized as diagnostic and prognostic hallmarks (9). In this study, we explored the biological function of IncRNA PICART1 in the malignant progression of $\mathrm{CC}$ and the potential mechanism.

\section{Patients and methods}

Sample collection and ethical statements. Sixty paired CC tissues and paracancerous tissues were surgically harvested from CC patients admitted to Weifang People's Hospital (Weifang, China) from March 2016 to October 2018. Tumor node metastasis (TNM) staging and tumor size of enrolled $\mathrm{CC}$ patients were recorded. None of these patients were preoperatively treated. This study was approved by the Medical Ethics Committee of Weifang People's Hospital and informed consent was received from each subject.

RNA extraction and $q R T-P C R$. Cells and tissues were lysed using TRIzol method (Invitrogen; Thermo Fisher Scientific, Inc.) for reverse transcription of RNAs using the PrimeScript RT reagent Kit (Takara). RNA was quantified using spectrometer and subjected to qRT-PCR following SYBR Premix Ex $\mathrm{Taq}^{\mathrm{TM}}$ (Takara). Relative level of target gene was determined by the $2^{-\Delta \Delta c t}$ method.

Cell culture and transfection. CC cell lines (HeLa, C4-1, SiHa, Caski) and normal cervical endothelial cell line (Etc1/E6E7) 
A $\quad$ B
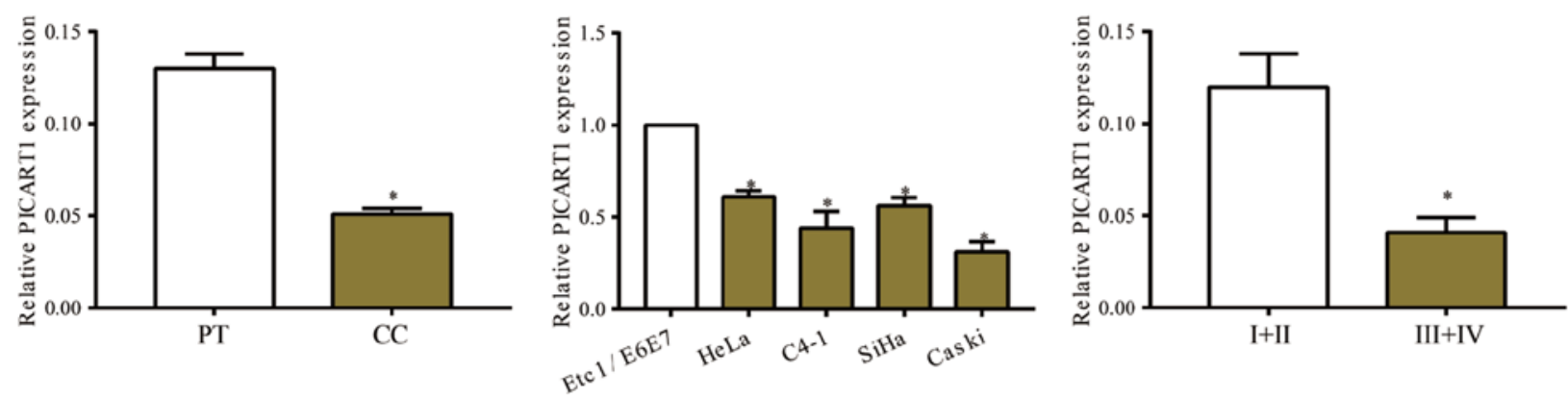

$\mathrm{D}$
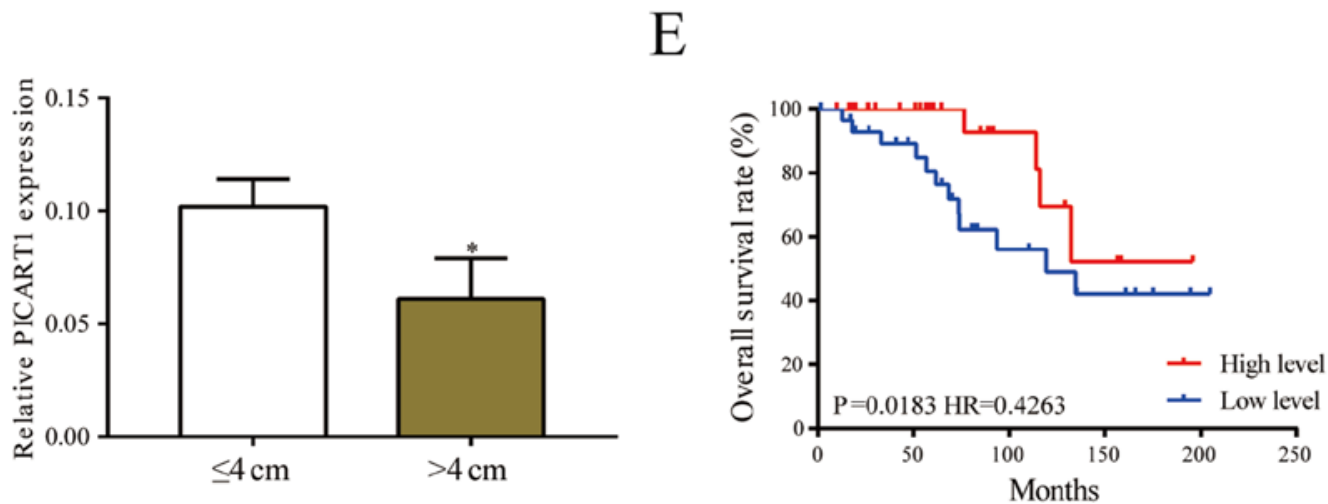

Figure 1. PICART1 is downregulated in CC. (A) Relative level of PICART1 in cervical cancer tissues and paracancerous tissues. PT, paracancerous tissues; CC, cervical cancer. (B) Relative level of PICART1 in cervical cancer cell lines (HeLa, C4-1, SiHa, Caski) and normal cervical endothelial cell line (Etc1/E6E7). (C) Relative level of PICART1 in cervical cancer patients with stage I+II and III+IV. (D) Relative level of PICART1 in cervical cancer tissues $\leq 4 \mathrm{~cm}$ and $>4 \mathrm{~cm}$ in tumor size. (E) Kaplan-Meier curves were introduced for assessing the overall survival in cervical cancer patients with high level and low level of PICART1. ${ }^{*} \mathrm{P}<0.05$.

were obtained from American Type Culture Collection (ATCC) (Manassas). Cell culture was conducted using Roswell Park Memorial Institute 1640 (RPMI-1640) medium (HyClone; GE Healthcare) with $10 \%$ fetal bovine serum (FBS) (Gibco; Thermo Fisher Scientific, Inc.) in an incubator with $5 \% \mathrm{CO}_{2}$ at $37^{\circ} \mathrm{C}$. For cell transfection, $1.5 \mathrm{ml}$ of serum-free medium and $0.5 \mathrm{ml}$ of Lipofectamine ${ }^{\mathrm{TM}} 2000$ (Invitrogen; Thermo Fisher Scientific, Inc.) containing transfection vectors were applied in each well of a 6-well plate. Fresh medium was replaced 4-6 h later. Transfected cells for 24-48 h were collected for determination.

Cell Counting Kit-8 (CCK-8) assay. Cell density was adjusted to $2 \times 10^{3}$ cells $/ 100 \mu \mathrm{l}$ and cells were inoculated in a $96-$ well plate. At the appointed times, cells per well were incubated with $10 \mu \mathrm{l}$ of CCK-8 solution (CCK-8, Dojindo Molecular Technologies, Inc.). Absorbance $(450 \mathrm{~nm})$ was recorded by a microplate reader (Bio-Rad Laboratories, Inc.).

Transwell assay. Suspension $\left(1.0 \times 10^{5}\right.$ cells $\left./ \mathrm{ml}\right)$ was prepared and subjected to serum starvation for $12 \mathrm{~h}$. Suspension (200 $\mu \mathrm{l} /$ well) was applied in the upper side of Transwell chamber (EMD Millipore) pre-coated with Matrigel. In the lower side, $700 \mu \mathrm{l}$ of medium containing 10\% FBS was applied. After $48 \mathrm{~h}$ of incubation, cells invaded to the lower side were subjected to fixation in methanol for $15 \mathrm{~min}$, crystal violet staining for $20 \mathrm{~min}$ and cell counting using a microscope. Invasive cells were counted in 5 randomly selected fields per sample. Migration assay was performed in the same way except for Matrigel pre-coating.

Determination of subcellular distribution. Cytoplasmic and nuclear RNAs were extracted using the PARIS kit (Invitrogen; Thermo Fisher Scientific, Inc.) and subjected to qRT-PCR. U6 was the internal reference of nucleus and glyceraldehyde 3-phosphate dehydrogenase (GAPDH) was that of cytoplasm.

RNA immunoprecipitation (RIP). Cells were treated according to the procedures of Millipore Magna RIP ${ }^{\mathrm{TM}}$ RNA-Binding Protein Immunoprecipitation kit (EMD Millipore). Cell lysate was incubated with antibodies or anti-IgG antibody at $4^{\circ} \mathrm{C}$ for $6 \mathrm{~h}$. A protein-RNA complex was captured and digested with $0.5 \mathrm{mg} / \mathrm{ml}$ proteinase $\mathrm{K}$ containing $0.1 \%$ sodium dodecyl sulphate (SDS) to extract RNA. The magnetic beads were repeatedly washed with RIP washing buffer to remove non-specific adsorption as much as possible. Finally, the extracted RNA was subjected to mRNA level determination using qRT-PCR.

Chromatin immunoprecipitation (ChIP). Cells were subjected to cross-link with $1 \%$ formaldehyde at room temperature for 10 min into small fractions with 200-300 bp. Subsequently, 
A

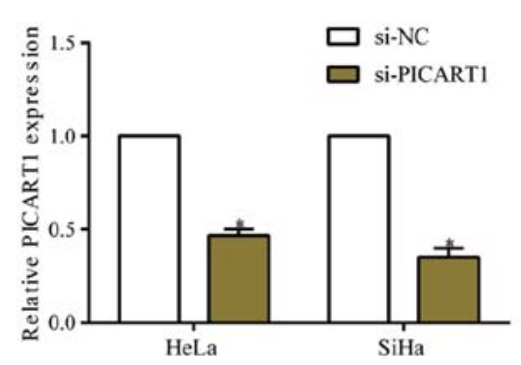

D

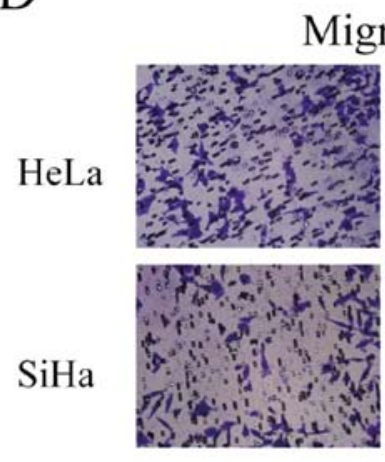

si-NC
B

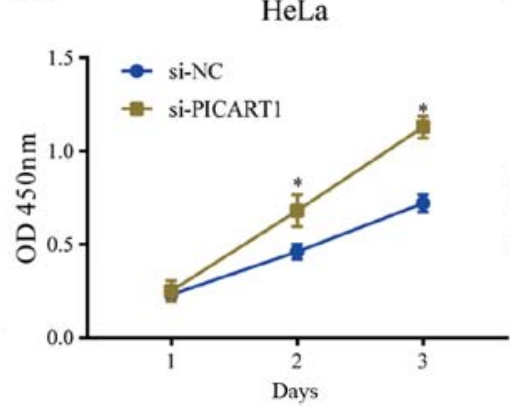

E

E
C

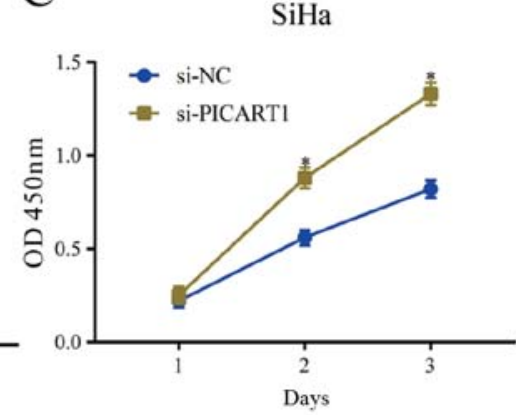

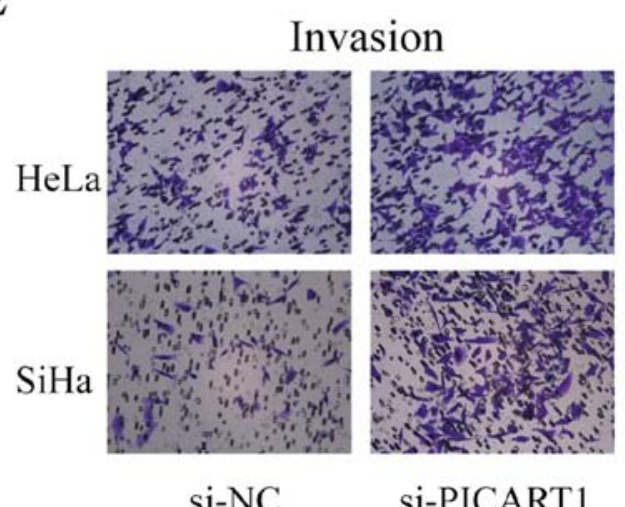

si-PICART 1

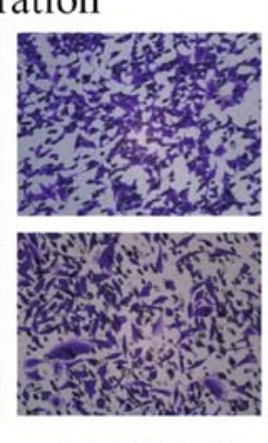

S1-NC

Figure 2. Silence of PICART1 accelerates proliferative, migratory and invasive abilities of CC. (A) Transfection efficacy of si-PICART1 in HeLa and SiHa cells. (B) CCK-8 assay showed viability in HeLa cells transfected with si-NC or si-PICART1. (C) CCK-8 assay showed viability in SiHa cells transfected with si-NC or si-PICART1. (D) Transwell assay shows the migration in HeLa and SiHa cells transfected with si-NC or si-PICART1. (E) Transwell assay shows the invasion in HeLa and SiHa cells transfected with si-NC or si-PICART1. CCK-8, Cell Counting Kit-8. ${ }^{*} \mathrm{P}<0.05$.

cells were lysed and sonicated for $30 \mathrm{~min}$. Finally, the sonicated lysate was immuno-precipitated with anti-TCF21, anti-ARID1A or anti-IgG. Purified immunoprecipitated chromatins were subjected to qRT-PCR.

Western blotting. Cells were lysed using radioimmunoprecipitation assay (RIPA) and extracted protein was quantified by bicinchoninic acid (BCA) method (Beyotime Institute of Biotechnology). Electrophoresis was conducted for transferring proteins on a polyvinylidene fluoride (PVDF) membranes (EMD Millipore). After 2-h blockage of non-specific sites in $5 \%$ skim milk, membranes were reacted with primary and secondary antibodies. Band exposure was achieved by electrochemiluminescence (ECL) and analyzed by Image Software (National Institutes of Health).

Statistical analysis. Statistical Product and Service Solutions (SPSS) 22.0 statistical software (IBM Corp.) was used for data analysis. Data were expressed as mean \pm standard deviation (mean $\pm \mathrm{SD}$ ). Intergroup data were compared using the t-test. Kaplan-Meier curves were employed for survival analysis. Pearson's correlation analysis was conducted for evaluating the relationship between two genes. $\mathrm{P}<0.05$ was considered to indicate a statistically significant difference.

\section{Results}

PICART1 is downregulated in CC. Expression level of PICART1 was determined in 60 paired CC tissues. PICART1 was downregulated in $\mathrm{CC}$ tissues relative to paracancerous ones (Fig. 1A). Identically, its level remained lower in CC cell lines than that of normal cervical endothelial cell line (Fig. 1B). PICART1 was found to be closely related to clinical characteristics of CC patients. Relative to CC patients in stage I+II, those in stage III+IV presented lower level of PICART1 (Fig. 1C). Lower abundance of PICART1 was observed in $\mathrm{CC}$ tissues larger than $4 \mathrm{~cm}$ in tumor size (Fig. 1D). Survival analysis showed worse prognosis in CC patients with low level of PICART1 (Fig. 1E).

Silence of PICART1 accelerates proliferative, migratory and invasive abilities of $C C$. We constructed si-PICART1 and tested its transfection efficacy. Transfection of si-PICART1 greatly downregulated PICART1 level in HeLa and SiHa cells (Fig. 2A). The viability in CC cells was markedly elevated after silence of PICART1 (Fig. 2B and C). Similarly, the migratory and invasive abilities of CC cells were accelerated after transfection of si-PICART1 (Fig. 2D and E).

PICART1 positively regulates TCF21 level. Compared with paracancerous tissues, TCF21 expression was low in CC tissues (Fig. 3A). A positive correlation between expression levels of TCF21 and PICART1 was observed in CC tissues $\left(\mathrm{R}^{2}=0.236, \mathrm{P}<0.001\right.$, Fig. 3B). Transfection of si-PICART1 downregulated both mRNA and protein level of TCF21 in HeLa and SiHa cells (Fig. 3C). Kaplan-Meier curves revealed worse prognosis in CC patients expressing low level of TCF21 
A

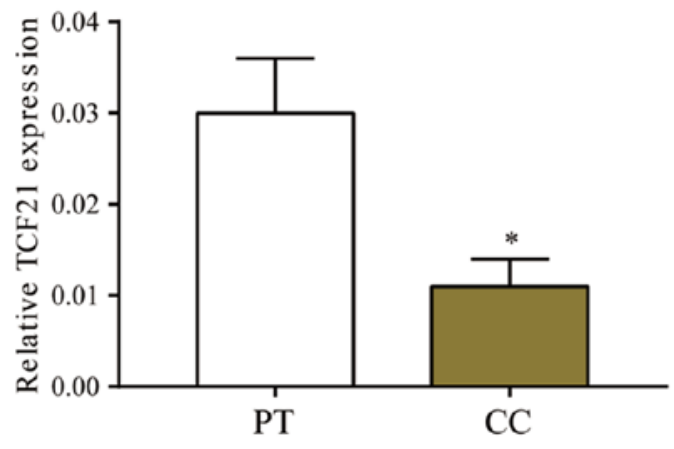

$\mathrm{C}$

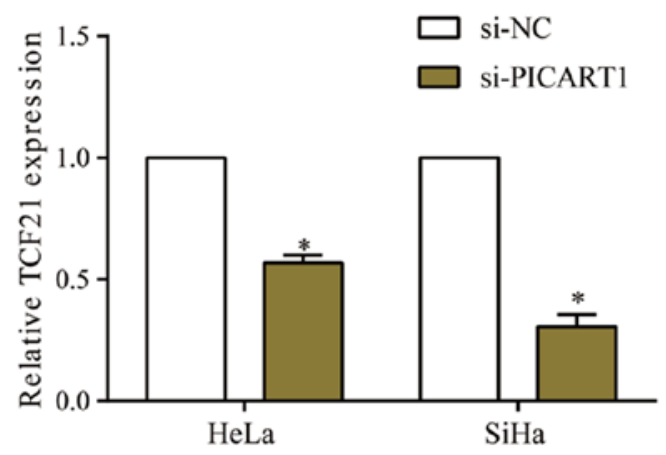

$\mathrm{B}$

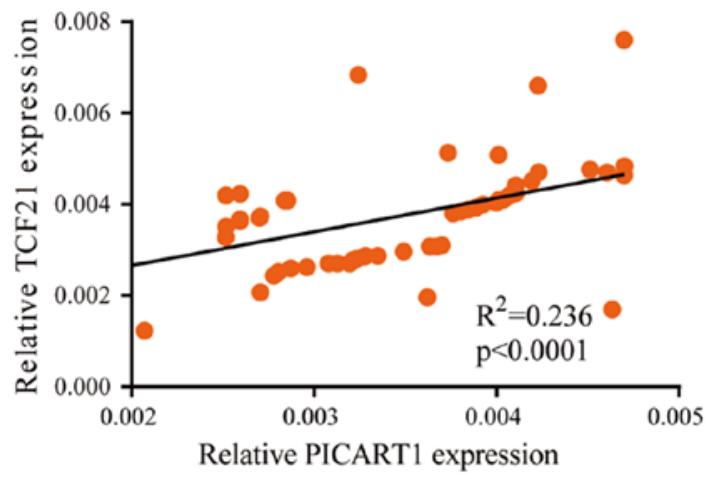

$\mathrm{D}$

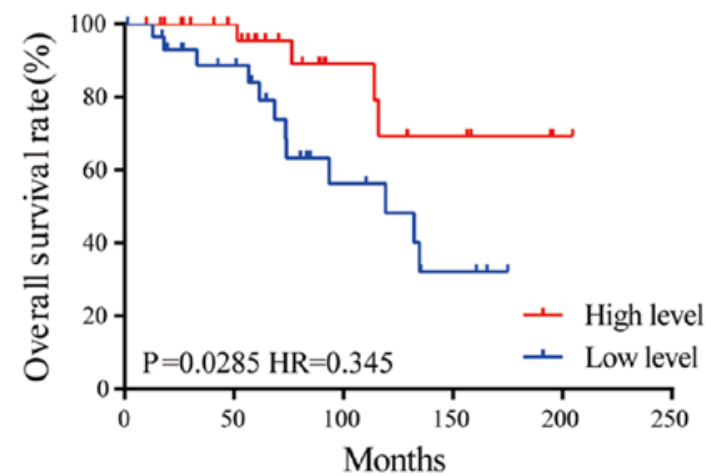

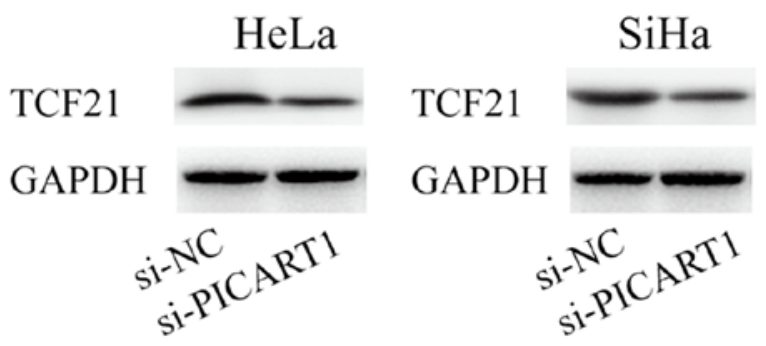

Figure 3. PICART1 positively regulates TCF21 level. (A) Relative level of TCF21 in cervical cancer tissues and paracancerous tissues. (B) A positive correlation between expression levels of TCF21 and PICART1 in CC tissues $\left(\mathrm{R}^{2}=0.236, \mathrm{P}<0.001\right)$. (C) Relative level of TCF21 in HeLa and SiHa cells transfected with si-NC or si-PICART1. (D) Kaplan-Meier curves introduced for assessing the overall survival in cervical cancer patients with high level and low level of TCF21. PT, paracancerous tissues; CC, cervical cancer. ${ }^{*} \mathrm{P}<0.05$.

(Fig. 3D). It is believed that TCF21 is closely related to the malignant progression of CC.

PICART1 recruites ARIDIA to activate TCF 21 expression. Subcellar distribution analysis showed that PICART1 was mainly expressed in nuclear fraction of HeLa cells (Fig. 4A). We next explored the possible functions of PICART1 and TCF21 in the progression of CC. Analysis of the DNA sequences in TCF21 promoter region showed a remarkable enrichment of PICART1 from -1000 to -500 bp (Fig. 4B). Moreover, the interaction between PICART1 and ARID1A was also identified (Fig. 4C and D). Potential binding sites were verified among PICART, ARID1A and TCF21. ChIP assay confirmed the decreased enrichment of ARID1A in TCF21 promoter region after PICART1 knockdown (Fig. 4E and F).

\section{Discussion}

CC ranks fourth in the morbidity and mortality of malignant tumors throughout the world. The prognosis of $\mathrm{CC}$ is unsatisfactory. Many genes, factors and pathways are involved in tumorigenesis of CC. It is of great significance to seek effective diagnostic and prognostic markers for CC.

A large number of observational studies have been conducted to identify the potential role of lncRNAs related to CC. For example, serum level of 1ncRNA PVT1 is upregulated in CC patients, which exerts diagnostic potential with 71.6 sensitivity and $98.8 \%$ specificity (10). IncRNA XLOC_010588 is downregulated in CC patients and predicts poor prognosis (11). In this study, IncRNA PICART1 was downregulated in CC tissues and cell lines. Silence of PICART1 accelerated the proliferative, migratory and invasive abilities of HeLa and SiHa cells. 
A

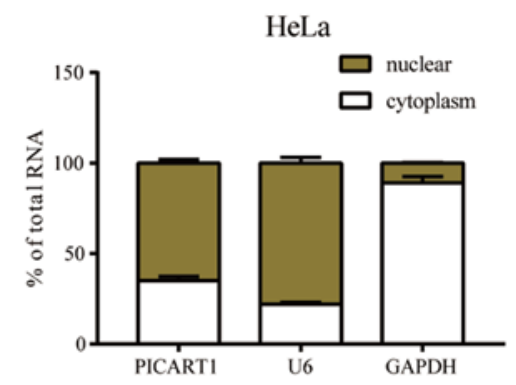

D

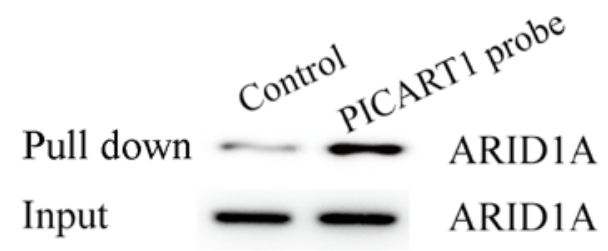

B

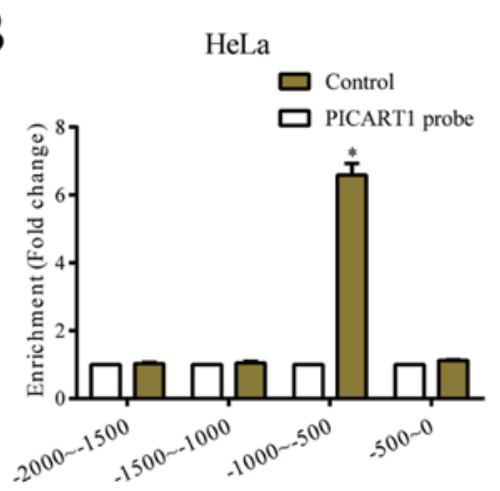

E

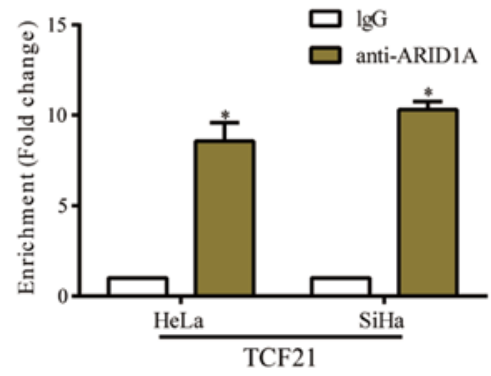

C

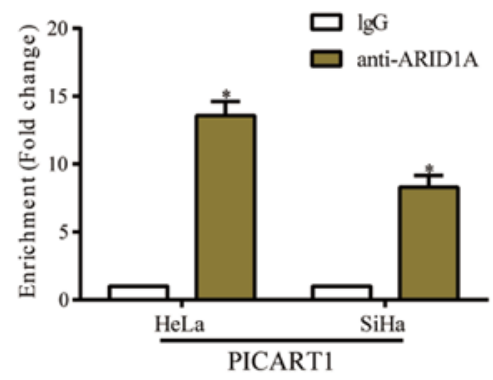

F

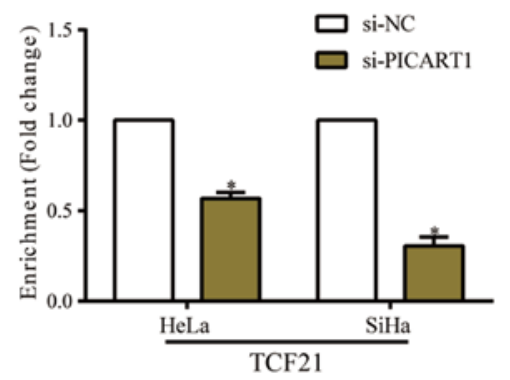

Figure 4. PICART1 recruites ARID1A to activate TCF21 expression. (A) Subcellular distribution of PICART1 in nuclear and cytoplasmic fraction of HeLa cells. U6 is the nuclear internal reference and GAPDH is that of the cytoplasm. (B) Enrichment of PICART1 in TCF21 promoter region. (C) Enrichment of PICART1 in anti-IgG and anti-ARID1A in HeLa and SiHa cells. (D) Relative level of ARID1A in PICART1 promoter region. (E) Enrichment of TCF21 in anti-IgG and anti-ARID1A in HeLa and SiHa cells. (F) Relative level of TCF21 in HeLa and SiHa cells transfected with si-NC or si-PICART1. P<0.05.

TCF21 was found to be the target gene of PICART1. TCF21, also known as Pod-1, capsuling and epicardin, mediates cell differentiation and apoptosis by binding to DNAs in the developmental process (12). TCF21 is mainly expressed in the embryonic mesenchymal cells around the kidney, heart, lung and gastrointestinal epithelial developmental areas $(13,14)$. Its level rapidly decreases after birth except for that in kidney, heart, lung and spleen stromal cells (15). Antisense inhibition of TCF21 has been reported to disrupt epithelial differentiation and branching morphogenesis in epithelial cells in mouse embryonic kidneys, suggesting that TCF21 could influence the process of EMT (16). TCF21 deficiency in the kidney results in decreased glomerulogenesis and tubular formation (17). Notably, transfection of TCF21 siRNA in mesenchymal progenitor cells from mouse kidney stimulates proliferative and migratory abilities, as well as downregulates expression of smooth muscle and myofibroblast secreted proteins (15). In clinical trials, ARID1A mutation is believed to be closely related to poor prognosis of ovarian cancer patients, indicating its tumor-suppressor role $(18,19)$. ARID1A protects genomic stability and antagonizes the carcinogenic role of EZH2 in clear cell carcinoma of ovary $(20,21)$. In addition, ARID1A as a priority guides SWI/SNF complexes H3K27ac- and $\mathrm{H} 3 \mathrm{~K} 4 \mathrm{me1}$-labeled enhancers to interact with multiple transcriptional factors (22). Owing to the dislocation of SWI/ SNF complexes to enhancers, ARID1A deficiency astimulates the progression of adenocarcinoma of colon in mice. Herein, our study found that PICART1 recruited ARID1A to activate TCF21 expression, thus alleviating the progression of CC. It is noteworthy that PICART1 shows ability to mediate a series of downstream genes. RNA sequencing of downstream targets after silencing of PICART1 is necessary.

In conclusion, lncRNA PICART1 is downregulated in CC tissues, and closely related to disease progression. PICART1 recruits ARID1A to activate TCF21 expression, thus alleviating the malignant progression of cervical cancer. It is believed that PICART1 may be utilized as a new drug target for $\mathrm{CC}$.

\section{Acknowledgements}

Not applicable.

\section{Funding}

No funding was received.

\section{Availability of data and materials}

All data generated or analyzed during this study are included in this published article.

\section{Authors' contributions}

YZ and RH designed the study and performed the experiments, YZ and XD collected the data, RH and XD analyzed the data, YZ and RH prepared the manuscript. All authors read and approved the final manuscript. 


\section{Ethics approval and consent to participate}

This study was approved by the Ethics Committee of Weifang People's Hospital (Weifang, China). Signed informed consents were obtained from the patients and/or the guardians.

\section{Patients consent for publication}

Not applicable.

\section{Competing interests}

The authors declare that they have no competing interests.

\section{References}

1. Torre LA, Bray F, Siegel RL, Ferlay J, Lortet-Tieulent J and Jemal A: Global cancer statistics, 2012. CA Cancer J Clin 65: 87-108, 2015.

2. Tian JDC and Liang L: Involvement of circular RNA SMARCA5/ microRNA-620 axis in the regulation of cervical cancer cell proliferation, invasion and migration. Eur Rev Med Pharmacol Sci 22: 8589-8598, 2018.

3. Siegel R, Naishadham D and Jemal A: Cancer statistics, 2013. CA Cancer J Clin 63: 11-30, 2013.

4. Salvatici M, Achilarre MT, Sandri MT, Boveri S, Vanna Z and Landoni F: Squamous cell carcinoma antigen (SCC-Ag) during follow-up of cervical cancer patients: Role in the early diagnosis of recurrence. Gynecol Oncol 142: 115-119, 2016.

5. Solans L, Gonzalo-Asensio J, Sala C, Benjak A, Uplekar S, Rougemont J, Guilhot C, Malaga W, Martín C and Cole ST: The PhoP-dependent ncRNA Mcr7 modulates the TAT secretion system in Mycobacterium tuberculosis. PLoS Pathog 10: e1004183, 2014.

6. Schwartz S, Bernstein DA, Mumbach MR, Jovanovic M, Herbst RH, León-Ricardo BX, Engreitz JM, Guttman M, Satija R, Lander ES, et al: Transcriptome-wide mapping reveals widespread dynamic-regulated pseudouridylation of ncRNA and mRNA. Cell 159: 148-162, 2014.

7. Lei B, Xu SP, Liang XS, Li YW, Zhang JF, Zhang GQ and Pang D: Long non-coding RNA MVIH is associated with poor prognosis and malignant biological behavior in breast cancer. Tumour Biol 37: 5257-5264, 2016.

8. Jalali S, Bhartiya D, Lalwani MK, Sivasubbu S and Scaria V: Systematic transcriptome wide analysis of lncRNA-miRNA interactions. PLoS One 8: e53823, 2013.

9. Chi S, Shen L, Hua T, Liu S, Zhuang G, Wang X, Zhou X, Wang $G$ and Wang $H$ : Prognostic and diagnostic significance of lncRNAs expression in cervical cancer: A systematic review and meta-analysis. Oncotarget 8: 79061-79072, 2017.
10. Yang JP, Yang XJ, Xiao L and Wang Y: Long noncoding RNA PVT1 as a novel serum biomarker for detection of cervical cancer. Eur Rev Med Pharmacol Sci 20: 3980-3986, 2016.

11. Liao LM, Sun XY, Liu AW, Wu JB, Cheng XL, Lin JX, Zheng M and Huang L: Low expression of long noncoding XLOC_010588 indicates a poor prognosis and promotes proliferation through upregulation of c-Myc in cervical cancer. Gynecol Oncol 133: 616-623, 2014.

12. Hidai H, Bardales R, Goodwin R, Quertermous $\mathrm{T}$ and Quertermous EE: Cloning of capsulin, a basic helix-loop-helix factor expressed in progenitor cells of the pericardium and the coronary arteries. Mech Dev 73: 33-43, 1998.

13. Lu J, Richardson JA and Olson EN: Capsulin: A novel bHLH transcription factor expressed in epicardial progenitors and mesenchyme of visceral organs. Mech Dev 73: 23-32, 1998.

14. Quaggin SE, Vanden Heuvel GB and Igarashi P: Pod-1, a mesoderm-specific basic-helix-loop-helix protein expressed in mesenchymal and glomerular epithelial cells in the developing kidney. Mech Dev 71: 37-48, 1998.

15. Plotkin $\mathrm{M}$ and Mudunuri V: Pod1 induces myofibroblast differentiation in mesenchymal progenitor cells from mouse kidney. J Cell Biochem 103: 675-690, 2008.

16. Quaggin SE, Schwartz L, Cui S, Igarashi P, Deimling J, Post M and Rossant J: The basic-helix-loop-helix protein pod1 is critically important for kidney and lung organogenesis. Development 126: 5771-5783, 1999.

17. Cui S, Schwartz L and Quaggin SE: Pod1 is required in stromal cells for glomerulogenesis. Dev Dyn 226: 512-522, 2003.

18. Katagiri A, Nakayama K, Rahman MT, Rahman M, Katagiri H, Nakayama N, Ishikawa M, Ishibashi T, Iida K, Kobayashi H, et al: Loss of ARID1A expression is related to shorter progression-free survival and chemoresistance in ovarian clear cell carcinoma. Mod Pathol 25: 282-288, 2012.

19. Wiegand KC, Shah SP, Al-Agha OM, Zhao Y, Tse K, Zeng T, Senz J, McConechy MK, Anglesio MS, Kalloger SE, et al: ARID1A mutations in endometriosis-associated ovarian carcinomas. N Engl J Med 363: 1532-1543, 2010.

20. Bitler BG, Aird KM, Garipov A, Li H, Amatangelo M, Kossenkov AV, Schultz DC, Liu Q, Shih IeM, ConejoGarcia JR, et al: Synthetic lethality by targeting EZH2 methyltransferase activity in ARID1A-mutated cancers. Nat Med 21: 231-238, 2015.

21. Dykhuizen EC, Hargreaves DC, Miller EL, Cui K, Korshunov A Kool M, Pfister S, Cho YJ, Zhao K and Crabtree GR: BAF complexes facilitate decatenation of DNA by topoisomerase II $\alpha$. Nature 497: 624-627, 2013.

22. Mathur R, Alver BH, San Roman AK, Wilson BG, Wang X, Agoston AT, Park PJ, Shivdasani RA and Roberts CW: ARID1A loss impairs enhancer-mediated gene regulation and drives colon cancer in mice. Nat Genet 49: 296-302, 2017.

This work is licensed under a Creative Commons Attribution-NonCommercial-NoDerivatives 4.0 International (CC BY-NC-ND 4.0) License. 